\title{
Morphological and Functional Characterization of Hemocytes of the Black Sea Bivalves: \\ Pacific Oyster (Crassostrea gigas) and Mussel (Mytilus galloprovincialis)
}

\author{
Alexandra Y. Andreyeva, Ekaterina S. Kladchenko*, \\ Oksana Y. Vyalova and Tatiana A. Kukhareva \\ A. O. Kovalevsky Institute of Biology of the Southern Seas of RAS \\ Sevastopol, Russian Federation
}

Received 11.10.2019, received in revised form 10.11.2020, accepted 12.12.2020

\begin{abstract}
To understand the role that hemocytes play in processes of cellular immunity of bivalve mollusks, they should be accurately classified based on their morphological and physiological characteristics. The circulating hemocytes of the cultured Pacific oyster (Crassostrea gigas) and marine mussel (Mytilus galloprovincialis) were investigated using light microscopy and flow cytometry. In the mussel, two cell types, granulocytes and agranulocytes, were identified based on the presence of two subpopulations of cells differing by size and granularity level on light scatter plots. Light microscopic examination confirmed the presence of cells with cytoplasmic granules and cells without granulation in hemolymph of the mussel. In the oyster, light microscopy and flow cytometry revealed three types of hemocytes: agranulocytes, hyalinocytes, and granulocytes. The cells in the hemolymph of both species were mainly represented by agranular cells, which constituted $78.4 \pm 8.9 \%$ in the mussel and $86.7 \pm 2.7 \%$ (agranulocytes and hyalinocytes) in the oyster. Agranulocytes were the smallest cell type in the mussel and oyster. They were round-shaped and had large nuclei and narrow cytoplasm. Hyalinocytes of the oyster were larger and irregularly shaped, with eccentric nuclei. Granulocytes of both species contained numerous eosinophilic, basophilic, and mixed granules and formed pseudopodia. Flow cytometry showed that the agranular hemocytes of both species produced considerably fewer reactive oxygen species compared to granulocytes. Morphological and functional characterization of hemocytes of cultivated species improves the analysis of physiological state of bivalve mollusks farmed in the Black Sea region.
\end{abstract}

Keywords: hemocytes, flow cytometry, light microscopy, bivalves, reactive oxygen species.

(C) Siberian Federal University. All rights reserved

This work is licensed under a Creative Commons Attribution-NonCommercial 4.0 International License (CC BY-NC 4.0).

* Corresponding author E-mail address: kladchenko ekaterina@bk.ru ORCID: 0000-0001-7845-0165 (Andreyeva A.); 0000-0001-9476-6573 (Kladchenko E.); 0000-0002-8304-0029 (VyalovaO.); 0000-0001-7151-4402 (Kukhareva T.) 
Acknowledgements. The morphological and functional parameters of mussel hemocytes were studied to carry out State Assignment «Functional, metabolic, and toxicological aspects of survival of aquatic organisms and their populations in biotopes with various physical and chemical conditions» (state registration number 121041400077-1); the study of morphological and functional parameters of oyster hemocytes was supported by Grants Council of the President of the Russian Federation (Project MK-609.2020.4).

Citation: Andreyeva A. Y., Kladchenko E. S., Vyalova O. Y., Kukhareva T. A. Morphological and functional characterization of hemocytes of the Black Sea bivalves: Pacific oyster (Crassostrea gigas) and mussel (Mytilus galloprovincialis). J. Sib. Fed. Univ. Biol., 2021, 14(2), 182-194. DOI: 10.17516/1997-1389-0346

\title{
Морфологические и функциональные
}

характеристики гемоцитов двустворчатых

черноморских моллюсков устрицы (Crassostrea gigas)

и мидии (Mytilus galloprovincialis)

\author{
А.Ю. Андреева, Е. С. Кладченко, \\ О.Ю. Вялова, Т. А. Кухарева \\ Институт биологии южных морей \\ имени А. О. Ковалевского РАН \\ Российская Федеращия, Севастополь
}

\begin{abstract}
Аннотация. Понимание роли и функций гемоцитов в иммунном ответе требует их четкой классификации, основанной на морфологических и функциональных признаках. Циркулирующие гемоциты культивируемой тихоокеанской устрицы (Crassostrea gigas) и средиземноморской мидии (Mytilus galloprovincialis) исследованы с помощью световой микроскопии и проточной цитометрии. У мидий методом проточной цитометрии по показателям прямого и бокового рассеяния идентифицировано две субпопуляции с различным относительным размером и уровнем гранулярности. Исследование методом световой микроскопии подтвердило наличие в гемолимфе гранулярных и агранулярных гемоцитов. У устриц с помощью методов проточной цитометрии и световой микроскопии выявлено три типа гемоцитов: агранулоциты, гиалиноциты и гранулоциты. Основным типом клеток гемолимфы у обоих видов были агранулярные клетки (агранулоциты и гиалиноциты), составляющие 78,4 $\pm 8,9 \%$ у мидий и $86,7 \pm 2,7 \%$ у устриц. Среди гемоцитов агранулоциты имели наименьший диаметр как у мидий, так и у устриц. Агранулярные гемоциты как устриц, так и мидий имели округлую форму с крупными ядрами и узкой полоской цитоплазмы. Гиалиноциты устриц крупнее, с ацентрическими ядрами и неправильной формы. Гранулоциты обоих видов содержали многочисленные базофильные и(или) эозинофильные гранулы. Агранулярные гемоциты обоих видов характеризовались значительно меньшей способностью продуцировать активные формы кислорода по сравнению с гранулоцитами. Применение морфофункционального анализа гемоцитов моллюсков - объектов марикультуры
\end{abstract}


позволит существенно повысить точность оценки состояния культивируемых в черноморском регионе двустворчатых моллюсков.

Ключевые слова: гемоциты, проточная цитометрия, световая микроскопия, двустворчатые моллюски, активные формы кислорода.

Благодарности. Исследование морфологических и функциональных параметров гемоцитов мидии изучалось в рамках госзадания N121041400077-1 «Функциональные, метаболические и токсикологические аспекты существования гидробионтов и их популяций в биотопах с различным физико-химическим режимом». Исследование морфологических и функциональных параметров гемоцитов устрицы проводилось при финансовой поддержке гранта Президента Российской Федерации для государственной поддержки молодых российских ученых - кандидатов наук (номер проекта МК609.2020.4).

Цитирование: Андреева, А.Ю. Морфологические и функциональные характеристики гемоцитов двустворчатых черноморских моллюсков устрицы (Crassostrea gigas) и мидии (Mytilus galloprovincialis) / А.Ю. Андреева, Е.С. Кладченко, О.Ю. Вялова, Т.А. Кухарева // Журн. Сиб. федер. ун-та. Биология, 2021. 14(2). С. 182-194. DOI: 10.17516/1997-1389-0346

\section{Введение}

У двустворчатых моллюсков физиологические реакции на стрессовые факторы окружающей среды связаны с клетками, циркулирующими в гемолимфе (Hine, 1999; Le Guernic et al., 2020). Гемоциты двустворчатых моллюсков участвуют в процессах восстановления раковины, транспорта питательных веществ и внутренних защитных реакций (Carballal et al., 1997). Функциональная роль гемоцитов позволяет использовать данный тип клеток в качестве репрезентативной модели для оценки общего физиологического состояния моллюска (Rigonato et al., 2005; Auffret et al., 1989). Такая оценка обычно проводится по показателям неспецифического иммунитета (Gerdol et al., 2018) при помощи комплекса методов проточной цитометрии и световой микроскопии (Travers et al., 2008). В этой связи изучение защитных реакций для оценки состояния моллюсков особенно важно для коммерчески культивируемых видов. Для четкого понимания роли и функций гемоцитов у двустворчатых моллюсков требуется их точная классификация, основанная на морфологических и функциональных характеристиках. Классификации гемоцитов различных видов двустворчатых моллюсков посвящено множество работ (Hernández-Méndez et al., 2020; Wang et al., 2017). Однако номенклатура клеток в гемолимфе моллюсков все еще остается предметом обсуждения (Hine, 1999; Rolton et al., 2020). Различия в классификации гемоцитов у разных (а иногда и одного) вида зависят от метода анализа и принципа, положенного в основу классификации клеток (Karetin et al., 2019; Donaghy et al., 2009; Carballal et al., 1997). Идентификация типов клеток гемолимфы обычно основывается на различных морфологических (ультраструктура, особенности окраски, размер, форма и т. д.) и функциональных характеристиках (способность к фагоцитозу, генерации окислительного взрыва и т. д.). Описание морфотипов гемоцитов не дает представления об их функциональной роли. Функциональный подход к характеристике гемоцитов основан на определении физиологических особенностей каждого типа 
клеток в организме (Pipe, 1990). Общепринятым подходом, используемым для функциональной характеристики гемоцитов, является проточная цитометрия (Ottaviani et al., 1998; Lambert et al., 2003; Parrino et al., 2019).

B семействе Mytilidae морфологический подход позволил выделить от одного до пяти типов гемоцитов (Carballal et al., 1997; Pipe, 1990; Нine, 1999). Исследование методом проточной цитометрии подтверждает существование двух основных типов клеток в гемолимфе мидий (Ottaviani et al., 1998). У семейства Ostreidae идентифицируют от трех до пяти типов гемоцитов с помощью световой микроскопии. Методом проточной цитометрии у устриц идентифицируют от двух до четырех типов гемоцитов (Lambert et al., 2003; Rolton et al., 2020; Takahashi et al., 2017).

Многочисленные различия в номенклатуре не позволяют составить целостное представление о функциональной роли каждого типа гемоцитов. Вместе с тем, информация о морфофункциональных особенностях клеток гемолимфы необходима для понимания результатов оценки показателей функционального состояния гемоцитов. Последнее приобретает особую актуальность при оценке физиологического состояния двустворчатых моллюсков в условиях аквакультуры.

В настоящем исследовании гемоциты двух черноморских двустворчатых моллюсков (Mytilus galloprovincialis и Crassostrea gigas) мы охарактеризовали с помощью световой микроскопии, градиентного центрифугирования и проточной цитометрии.

\section{Материалы и методы}

Взятие образцов

Мидии (M. galloprovincialis) и устрицы (C. gigas) были получены с устрично-мидийной фермы (соленое озеро Донузлав, Крым) в те- чение октября - ноября 2017 г. Группы по 1520 особей содержались в аэрируемой морской воде в аквариумах по 50 л в течение недели для адаптации к лабораторным условиям.

Отбор проб гемолимфы

Гемолимфу мидий $(0,1-1,5$ мл) отбирали из переднего мускула-замыкателя. В опытах с мидиями анализировали объединенную гемолимфу от 3-5 моллюсков. Гемолимфу устриц (1-1,5 мл) отбирали из сердечного синуса. Все образцы хранили на льду для предотвращения агрегации гемоцитов. После отбора гемолимфу фильтровали через фильтр с диаметром ячейки 20 мкм для удаления агрегатов, дважды отмывали центрифугированием (5 мин, 2500 об/мин) и ресуспендировали в стерильной морской воде.

\section{Световая микроскопия}

Окраска мазков проводилась по комбинированному методу Паппенгейма (Золотницкая, 1987). Клетки изучали на световом микроскопе (Biomed PR-2 Lum), оборудованном камерой (Levenhuk C NG Series), анализировали не менее 1000 гемоцитов. Диаметр клеток и ядер измеряли в программе ImageJ 1.44 p. Ядерно-плазматическое отношение (ЯПО) рассчитывали по формуле

\section{ЯПО = Диаметр ядра / Диаметр гемоцита.}

\section{Проточная ичитометрия}

Для идентификации типов клеток, уровня смертности гемоцитов и способности клеток генерировать активные формы кислорода (АФК) суспензию гемоцитов разводили стерильной морской водой до концентрации $1-2 \cdot 10^{6}$ кл мл ${ }^{-1}$. Анализ проводили на проточном цитометре Beckman Counter FC500. Отсечение клеточного дебриса проводилось по по- 
рогу FSC, в каждом образце подсчитывалось 50000 событий.

Для идентификации клеток суспензию окрашивали ДНК-связывающим флуорохромом SYBR Green I (Molecular probes, США) согласно протоколу производителя (конечная концентрация в пробе составляла 10 мкМ). Результаты анализа представлены в виде цитограмм, отражающих относительный размер (прямое рассеяние, FSC), гранулярность (боковое рассеяние, SSC) и уровень флуоресценции с использованием канала FL1.

Уровень смертности гемоцитов определяли при помощи красителя Propidium iodide (PI) (Sigma-Aldrich, США). 10 мкл стокового раствора PI (200 мкг мл $\left.{ }^{-1}\right)$ добавляли к 1 мл суспензии гемоцитов и инкубировали в темноте в течение 30 мин при $4{ }^{\circ} \mathrm{C}$. Процент погибших гемоцитов оценивали по гистограммам флуоресценции PI в канале FL4 цитометра.

Для тестирования способности клеток к генерации АФК в качестве флуоресцентного индикатора использовали 2',7'-дихлорфлуоресцеин диацетат (DCF-DA) (Sigma-Aldrich, США). 1 мл суспензии гемоцитов инкубировали с 10 мкл раствора DCF- DA в течение 30 мин в темноте. Флуоресценция DCF-DA измерялась детектором FL1 проточного цитометра.

\section{Градиентное ичентрифугирование}

Субпопуляции гемоцитов обоих видов моллюсков разделяли градиентным центрифугированием в растворах Percoll (SigmaAldrich, США) различной плотности в соответствии с протоколом, используемым для гемоцитов моллюсков (Bachère et al., 1988). Клетки, сконцентрированные на каждом слое, собирали отдельно, для удаления частиц Percoll пробы дважды промывали в стерильной морской воде в течение 5 мин (2500 об/мин). Из осадка клеток готовили мазки, а оставшуюся его часть использовали для анализа на проточном цитометре.

\section{Статистический анализ}

Всего было проанализировано по 13 образцов гемолимфы каждого вида, результаты представлены в виде средней и стандартной ошибки. Нормальность распределения проверяли по критерию Шапиро-Уилка. Для сравнения характеристик различных субпопуляций гемоцитов, исследуемых методом световой микроскопии, был проведен односторонний дисперсионный анализ (ANOVA) и тест Тьюки. Значимость различий между средними значениями данных проточной цитометрии была оценена с использованием t-критерия Стьюдента. Различия считали достоверными при $\mathrm{p} \leq 0,05$.

\section{Результаты}

Клетки гемоцитов идентифицировали по положительной флуоресценции SYBR Green I, затем анализировали по графику прямого рассеяния (FSC) и бокового рассеяния (SSC). Гемоциты моллюсков были относительно однородными по содержанию ДНК. Диплоидный пик характеризовался низким коэффициентом вариации ( $\mathrm{CV}=9 \pm 0,8$ \%). Различия между образцами гемолимфы по относительному размеру и уровню гранулярности в пределах одного вида были недостоверны. Доля мертвых гемоцитов была низкой во всех образцах гемолимфы ( $\leq 10 \%)$.

В гемолимфе $M$. galloprovincialis обнаружены две субпопуляции гемоцитов (рис. $1 A$ ). Субпопуляция 1, идентифицированная как агранулоциты, состояла из небольших клеток с относительно однородной цитоплазмой. Клетки характеризовались близкими относительными диаметрами согласно значению FS и широким разбросом относительной гранулярности согласно значению $\mathrm{SS}$ (рис. $1 A$ ). 
A

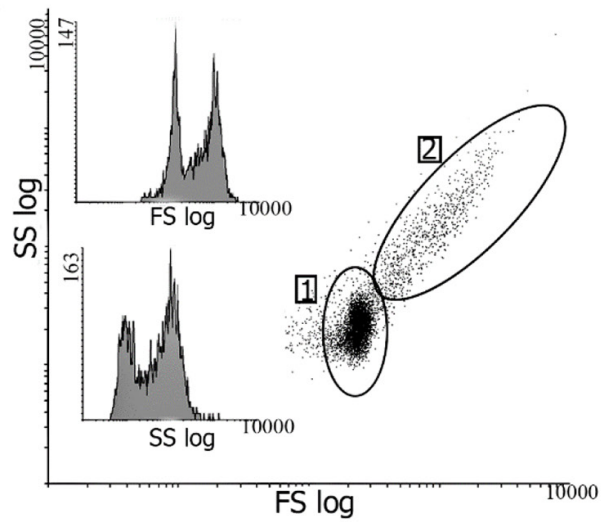

B

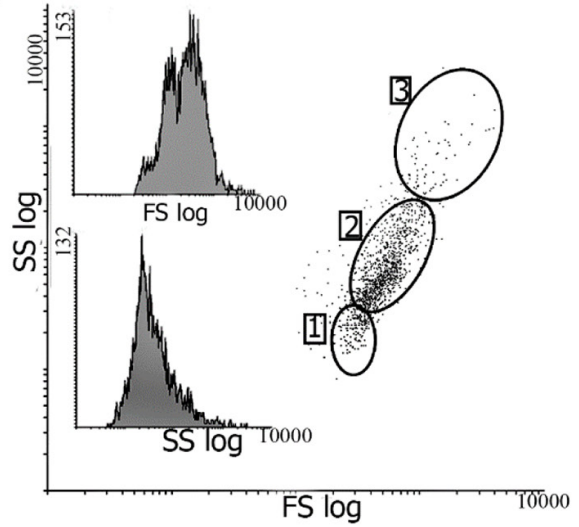

Рис. 1. Результаты проточной цитометрии гемоцитов M. galloprovincialis и C. gigas, окрашенных SYBR Green I: $A$ - диаграмма отношения прямого рассеяния (FSC) и бокового рассеяния (SSC), показывающая две субпопуляции гемоцитов (1 и 2) гемолимфы M. galloprovincialis; В - диаграмма отношения прямого рассеяния (FSC) и бокового рассеяния (SSC) гемоцитов C. gigas, показывающая три субпопуляции гемоцитов, обозначенные $1,2,3$. На врезках даны гистограммы распределения клеток по FSC и SSC

Fig. 1. Flow cytometer analysis of fresh hemocytes of $M$. galloprovincialis and $C$. gigas stained with SYBR Green I. (A) Forward scatter (FSC) vs. side scatter (SSC) density plot showing two hemocyte populations (1 and 2) of M. galloprovincialis hemolymph. (B) Forward scatter (FSC) vs. side scatter (SSC) density plot showing 3 hemocyte populations designated 1, 2, 3 of $C$. gigas hemocytes. Inset images show FSC and SSC distribution of the cells

Агранулоциты были наиболее многочисленной субпопуляцией $(78,4 \pm 8,9 \%)$. Субпопуляция 2 была идентифицирована как гранулоциты. Для данного типа клеток характерно высокое значение SS. Субпопуляция клеток с гранулированной цитоплазмой была гетерогенной по значениям FS и SS.

У C. gigas обнаружено три субпопуляции клеток разного размера (рис. 1В). Субпопуляция 1 , идентифицированная как агранулоциты, состояла из небольших гемоцитов с гомогенной цитоплазмой, которые составляли 24,3 $\pm 2,7 \%$. Субпопуляция 2 состояла из крупных агранулярных гемоцитов, которые составили $62,4 \pm 2,7 \%$ клеток от всех гемоцитов. Клетки данной субпопуляции идентифицированы как гиалиноциты. Субпопуляция 3, идентифицирована как гранулоциты, была самой малочисленной $(13,2 \pm 1,7$ \%). Последняя группа клеток имела наибольший относительный размер и уровень гранулярности.
Идентифицированные субпопуляции статистически значимо различались между собой по показателям FSC и SSC ( $\leq \leq 0,05 ; \mathrm{n}=13$ ).

Все клетки в суспензии гемолимфы мидий характеризовались выраженной флуоресценцией DCF-DA (рис. 2). Уровень флуоресценции гранулоцитов был в 2 раза выше, чем у агранулоцитов. Аналогично в гемолимфе устрицы все клетки обладали яркой флуоресценцией DCF-DA, но ее величина у субпопуляций различалась: флуоресценция красителя в клетках гиалиноцитов была в 3 раза выше в сравнении с агранулоцитами, а наибольшей способностью к генерации АФК в суспензии гемоцитов устриц обладали гранулоциты.

Методом световой микроскопии в гемолимфе устриц выделено три типа клеток: агранулоциты, гиалиноциты и гранулоциты. У мидий гемоциты можно разделить на две популяции: агранулоциты и гранулоциты (рис. 3). 


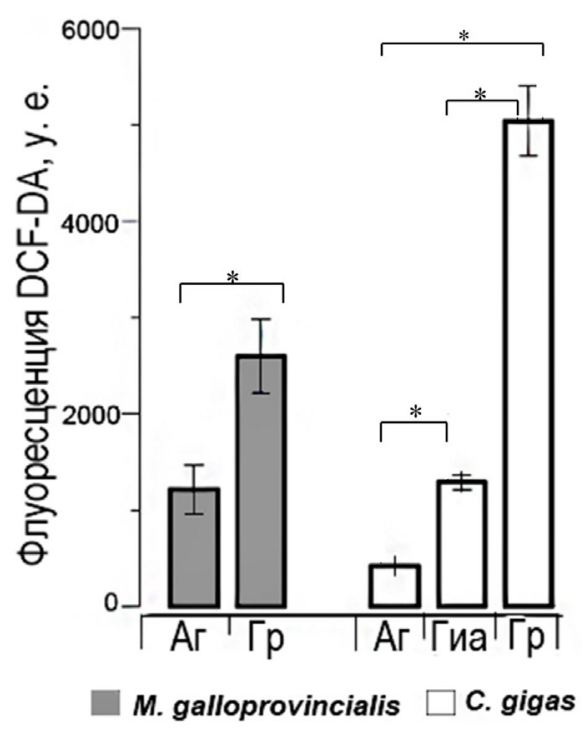

Рис. 2. Сравнение средней интенсивности флуоресценции DCF-DA (в условных единицах \pm SE) в нестимулированных гемоцитах M. galloprovincialis и C. gigas: Аг - агранулоциты, Гр - гранулоциты, Гиа - гиалиноциты. * - достоверные различия между уровнем флуоресценции различных типов клеток $(\mathrm{p} \leq 0,05)$

Fig. 2. Comparison of the mean DCF-DA fluorescence level (arbitrary units \pm SE) in non-stimulated hemocytes of M. galloprovincialis and C. gigas: Аг - agranulocyte, Гр - granulocyte, Гиа - hyalinocyte. * represents significant differences between average values of fluorescence of different cell types, $p \leq 0.05$

A

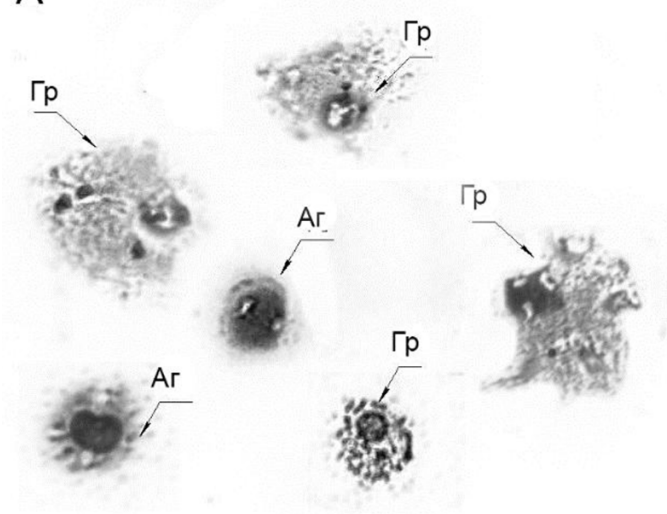

Б

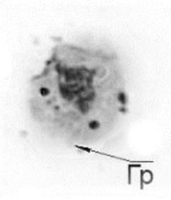

$\Gamma \underline{p}$

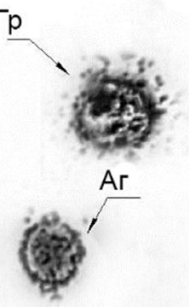

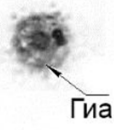

Гиа

Гиа

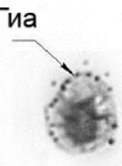

$\Gamma \underline{p}$

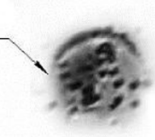

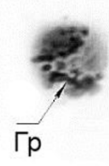

$\overline{\Gamma p}$

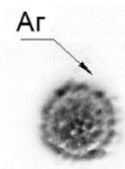

10 мкм

Рис. 3. Световые микрофотографии гемоцитов M. galloprovincialis (А) и C. gigas (Б): Аг - агранулоциты, Гр - гранулоциты, Гиа - гиалиноциты

Fig. 3. Light microphotographs of hemocytes of M. galloprovincialis (A) and C. gigas (B): Аг - agranulocytes, Гр-granulocytes, Гиа - hyalinocytes

Агранулоциты у исследуемых видов сходны по морфологии и имеют округлую форму с крупным ядром $(5,4 \pm 0,1$ мкм у мидий и 5,5 \pm 0,1 мкм у устриц), окруженным узкой полоской цитоплазмы (рис. 3, 4). ЯПО агранулоцитов устриц и мидий составляло $0,6 \pm$ 

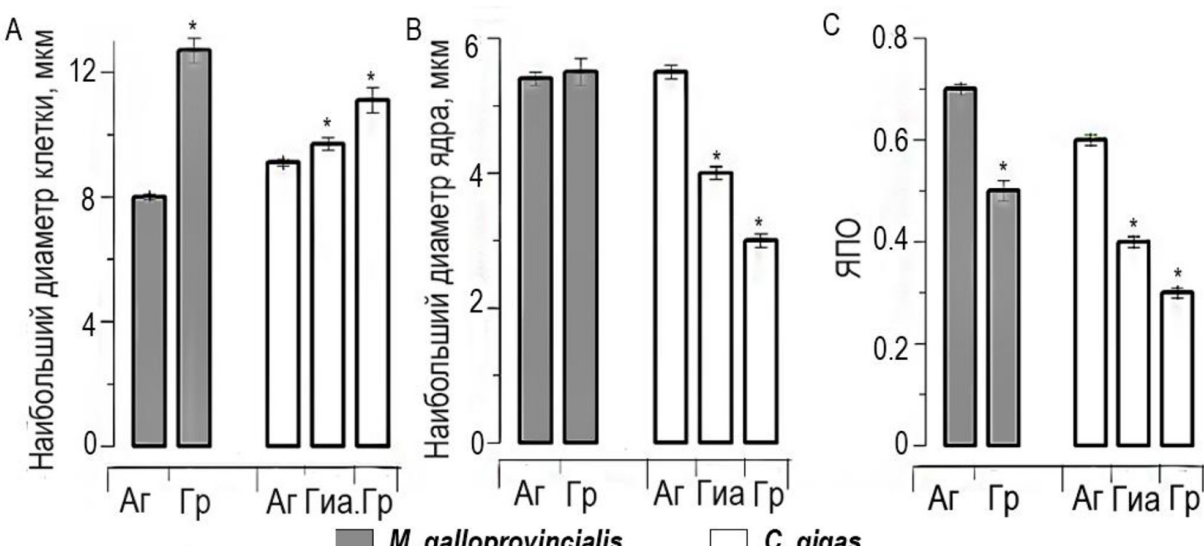

M. galloprovincialis

\section{C. gigas}

Рис. 4. Морфометрические показатели гемоцитов ( $\overline{\mathrm{x}} \pm \mathrm{SE})$ M. galloprovincialis и C. gigas, измеренные на мазках: Аг - агранулоциты, Гр - гранулоциты, Гиа-гиалиноциты. *-достоверные различия с тем же показателем для агранулоцитов $(\mathrm{p} \leq 0,05)$

Fig. 4. Dimensions of M. galloprovincialis and C. gigas hemocytes measured in slides ( $\overline{\mathrm{x}} \pm \mathrm{SE})$ : АГ-agranulocyte; Гиа - hyalinocyte; Гр - granulocyte. * - represents significant differences between the same parameters for agranulocytes, $\mathrm{p} \leq 0.05$

0,01 и $0,7 \pm 0,01$ соответственно. Гранулоциты обоих видов были относительно крупными клетками $(12,7 \pm 0,4$ мкм в диаметре у мидий и $11,1 \pm 0,4$ мкм у устриц), обладали амебоидной формой с небольшими ацентрическими ядрами, в цитоплазме содержались гранулы (рис. 3, 4). Количество гранул варьировало от 2 до 27. Большинство гранулоцитов содержали базофильные гранулы, однако также встречались клетки с эозинофильными гранулами. В некоторых случаях гранулоциты не имели псевдоподий. ЯПО гранулоцитов было относительно небольшим и составляло $0,5 \pm 0,02$ мкм у мидий и $0,3 \pm 0,01$ мкм У устриц. Гиалиноциты устриц имели промежуточный диаметр ядра (3,9 $\pm 0,1$ мкм) и ЯПО $(0,4 \pm 0,01)$ между агранулоцитами и гранулоцитами. Их морфологические признаки были схожи с гранулоцитами: способность образовывать псевдоподии, более низкое ЯПО в сравнении с агранулоцитами. Однако базофильные ядра гиалиноцитов расположены в центре клетки и цитоплазма не содержала гранул в отличие от гранулоцитов (рис. 3Б).
Несмотря на то, что средний диаметр агранулоцитов, гиалиноцитов и гранулоцитов значительно различался $(\mathrm{p}<0,05)$, в гемолимфе мидий и устриц мы наблюдали редкие агранулярные клетки с диаметром, близким к гранулоцитам. Аналогично некоторые гранулоциты были небольшими по сравнению с агранулоцитами. Диаметр гиалиноцитов у устриц варьировал в диапазоне, частично перекрывающемся с диапазоном размеров агранулоцитов и гранулоцитов.

Методом градиентного центрифугирования выделено три слоя гемоцитов в гемолимфе устриц и два слоя у мидий. Самый нижний слой (клетки с большей плотностью) содержал в основном гранулоциты и небольшое количество крупных агранулоцитов (у мидий) и гиалиноцитов (у устриц). Верхний слой образован клетками с наименьшей плотностью - агранулоцитами у обоих видов. У мидий этот слой также содержал несколько небольших гранулоцитов с небольшим числом гранул в цитоплазме (не более 7). Этот слой у устриц включал небольшое число гиа- 
линоцитов. Средний слой клеток, обнаруженный в устрицах, в основном был образован гиалиноцитами с небольшим содержанием агранулоцитов и гранулоцитов.

\section{Обсуждение}

Настоящая работа подтверждает гипотезу о сходстве проточно-цитометрических профилей гемоцитов у различных видов морских двустворчатых моллюсков (Hinzmann et al., 2017). В настоящее время предполагается, что у двустворчатых моллюсков два основных типа клеток: гранулоциты и агранулоциты (Hine, 1999; Hinzmann et al., 2017; Hernández-Méndez et al., 2020; Wang et al., 2017). Вместе с тем, представители семейства Ostreidae (Crassostrea virginica, Ostrea edulis) и других семейств двустворчатых моллюсков (Veneridae, Tridacnidae) имеют еще один тип гемоцитов, обычно называемый гиалиноцитами (Hine, 1999). Некоторые авторы определяют их как подгруппу агранулоцитов (Allam et al., 2002). Во многих работах термин «гиалиноциты» имеет более широкий смысл и обозначает все гемоциты, не содержащие гранулы (Chang et al., 2005). Мы классифицировали агранулоциты и гиалиноциты как агранулярные клетки с большим ядром. Гиалиноциты имели большое центрально расположенное ядро, не содержали гранул в цитоплазме, но в отличие от агранулоцитов были способны образовывать псевдоподии и обладали более низким ЯПО.

Результаты этого исследования показывают наличие трех типов гемоцитов у C. gigas: агранулоцитов, гиалиноцитов и гранулоцитов, что в целом согласуется с ранее опубликованными исследованиями гемолимфы устриц (Donaghy et al., 2012). Основные морфологические особенности гранулоцитов устриц были аналогичны тем, о которых уже сообщалось в других иссле- дованиях (Chang at al., 2005; Lambert et al., 2003; Rolton et al., 2020; Takahashi et al., 2017). Однако некоторые авторы подразделяли гранулоциты на базофильные, эозинофильные и смешанные клетки в соответствии с цветом гранул (Chang at al., 2005). Несмотря на то, что мы наблюдали гранулоциты с гранулами разного цвета, мы не использовали этот морфологический критерий для различения субпопуляций, поскольку он мог быть субъективным. Кроме того, и метод градиентного центрифугирования, и проточная цитометрия гемолимфы позволили выделить только три типа клеток. Мы разделили агранулярные клетки на два морфологических типа: агранулоциты (более мелкие) и гиалиноциты (более крупные агранулярные клетки). Гиалиноциты и гранулоциты устриц имели клеточный и ядерный диаметры, сходные с найденными в предыдущих работах, исследовавших гемоциты C. gigas (Chang at al., 2005) и C. virginica (Allam et al., 2002). В еще одном исследовании (Donaghy et al., 2012) было показано, что гемолимфа устриц может содержать также и другие агранулированные клетки, такие как везикулярные (вакуолизированные) и бластоподобные клетки. В настоящей работе агранулоциты имели широкий разброс диаметра клеток (от 4 до 20 мкм), а самые маленькие клетки имели диаметр и морфологию, близкие к бластоподобным гемоцитам. Однако до настоящего момента неизвестно, способны ли бластоподобные агранулоциты, подобно стволовым клеткам позвоночных, дифференцироваться в другие типы гемоцитов, а данные об иммунологических или молекулярных маркерах, представленных на этих клетках, противоречивы (Hine, 1999; Hernández-Méndez et al., 2020; Wang et al., 2017). Используемые методы и клеточные параметры, изученные в настоящей работе, не позволили нам выделить 
мелкие агранулоциты в отдельную группу, поэтому мы идентифицировали их как часть субпопуляции агранулоцитов.

Результаты исследования гемоцитов $M$. galloprovincialis методами световой микроскопии и проточной цитометрии указывают на наличие двух разных типов гемоцитов: клеток без включений и гранулированных клеток. Результаты центрифугирования в градиенте Percoll показали, что клетки в гемолимфе могут быть разделены по их плотности. Настоящее исследование согласуется с предыдущими результатами: диаметр клеток и ЯПО гемоцитов близки к тем, которые были получены в работе (Carballal et al., 1997). В семействе Mytilidae были выделены два типа гемоцитов: агранулоциты или гиалиноциты и гранулоциты (Ottaviani et al., 1998). Подобно устрицам, гранулоциты мидий можно классифицировать по цвету (Carballal et al., 1997), количеству и размеру гранул (Ріре, 1990). Мы также наблюдали гемоциты с различной степенью грануляции и окраски базофильных и эозинофильных гранул.

Функциональная роль каждой субпопуляции гемоцитов у двустворчатых моллюсков до конца не изучена. Нами установлено, что гранулоциты и гиалиноциты как $M$. galloprovincialis, так и C. gigas вносили вклад в генерацию АФК, но гранулоциты, повидимому, являются наиболее активными клетками-производителями. Это согласуется с исследованиями других видов двустворчатых моллюсков, таких как Crassostrea ariakensis и Lamellidens marginalis (Donaghy et al., 2009). Роль гранулоцитов в иммунной защите мидий может соответствовать их способности к цитотоксическому действию в отношении условных патогенов. Например, показано (Pipe, 1992), что у Mytilus edulis и M. galloprovincialis продукция АФК напрямую связана с фагоцитозом. Предположительно гранулоциты играют центральную роль в клеточном иммунитете у двустворчатых моллюсков (Nakahara et al., 2009; Gerdol et al., 2018). Специфические функции гиалиноцитов и агранулоцитов пока не ясны. Некоторые авторы предполагают, что агранулярные гемоциты являются незрелыми гранулоцитами (Ottaviani et al., 1998). В нашей работе показано, что агранулоциты и гиалиноциты мидий и устриц обладают большим ЯПО, чем гранулоциты. Известно, что незрелые клетки крови низших позвоночных (Andreyeva et al., 2017) и млекопитающих (Van der Knaap et al., 1993) обычно характеризуются высоким ЯПО и базофильной цитоплазмой. Тем не менее участки кроветворения у двустворчатых моллюсков не идентифицированы, а пролиферация гемоцитов в циркулирующей гемолимфе все еще считается патологией (Muttray, Vassilenko, 2018). Очевидно, что существует гетерогенность в морфологии гранулоцитов и гиалиноцитов у $M$. galloprovincialis и $C$. gigas. Эти подтипы клеток могут быть различными стадиями созревания клеток либо быть результатом функциональной специализации гемоцитов. Отсутствие отдельных субпопуляций клеток на графиках светорассеяния может указывать на то, что агранулоциты, гиалиноциты и гранулоциты устриц являются частями одной и той же клеточной линии. Фактически «промежуточная» клеточная группа присутствует и идентифицируется как гиалиноциты, которые имеют более низкое ЯПО по сравнению с агранулоцитами, не имеют грануляции, но способны образовывать псевдоподии. Однако полученных результатов недостаточно для того, чтобы утверждать, что гранулоциты являются зрелой стадией агранулярных клеток в гемолимфе M. galloprovincialis и C. gigas. 


\section{Заключение}

Таким образом, в нашей работе проанализированы параметры гемоцитов у устриц C. gigas и мидий M. galloprovincialis. Гемолимфа M. galloprovincialis содержала в основном мелкие агранулоциты (в среднем около $80 \%$ ) и около $22 \%$ крупных гранулоцитов с псевдоподиями. У C. gigas выделено три субпопуляции гемоцитов, среди которых агранулярные клетки (агранулоциты и гиалиноциты) были доминирующим типом клеток. Результаты исследования показывают сходство между морфологией и функциональными свойствами гемоцитов устриц и мидий. Для агранулярных клеток характерно отсутствие гранул в цитоплазме и более высокое по сравнению с гранулоци- тами ЯПО. Гранулоциты способны образовывать псевдоподии, содержат большое число гранул в цитоплазме и имеют небольшое ацентричное ядро. Как гранулярные, так и агранулярные клетки обоих видов исследованных моллюсков обладали способностью к продукции АФК. Гиалиноциты устриц обладали свойствами промежуточной стадии дифференциации между агранулоцитами и гранулоцитами: не содержали гранул в цитоплазме, ядро располагалось в центре клетки, были способны образовывать псевдоподии. Полученные результаты являются научной основой, необходимой для анализа функционального состояния культивируемых в черноморском регионе двустворчатых моллюсков.

\section{Список литературы / References}

Золотницкая Р.П. (1987) Методы гематологических исследований. Лабораторные методы исследования в клинике. Меньшиков В. В. (ред.) Москва, Медицина, с. 110-122 [Zolotntskaya R. P. (1987) Methods of hematological studies. Laboratory research methods in the clinic. Men'shikov V.V. (ed.) Moscow, Meditsina, p. 110-122 (in Russian)]

Allam B., Ashton-Alcox K.A., Ford S. E. (2002) Flow cytometric comparison of haemocytes from three species of bivalve molluscs. Fish \& Shellfish Immunology, 13(2): 141-158

Andreyeva A. Y., Soldatov A. A., Kukhareva T. A. (2017) Black Scorpionfish (Scorpaena porcus) hemopoiesis: analysis by flow cytometry and light microscopy. The Anatomical Record, 300(11): 19931999

Auffret M. (1989) Comparative study of the hemocytes of two oyster species: the European flat oyster, Ostrea edulis Linnaeus, 1750 and the Pacific oyster, Crassostrea gigas (Thunberg, 1793). Journal of Shellfish Research, 8: 367-373

Bachere E., Chagot D., Grizel H. (1988) Separation of Crassostrea gigas hemocytes by density gradient centrifugation and counterflow centrifugal elutriation. Developmental \& Comparative Immunology, 12(3): 549-559

Carballal M. J., Lopez M. C., Azevedo C., Villalba A. (1997) Hemolymph cell types of the mussel Mytilus galloprovincialis. Diseases of Aquatic Organisms, 29(2): 127-135

Chang S. J., Tseng S. M., Chou H. Y. (2005) Morphological characterization via light and electron microscopy of the hemocytes of two cultured bivalves: a comparison study between the hard clam (Meretrix lusoria) and Pacific oyster (Crassostrea gigas). Zoological Studies, 44(1): 144-152

Donaghy L., Kim B. K., Hong H. K., Park H. S., Choi K. S. (2009) Flow cytometry studies on the populations and immune parameters of the hemocytes of the Suminoe oyster, Crassostrea ariakensis. Fish \& Shellfish Immunology, 27(2): 296-301 
Donaghy L., Kraffe E., Le Goïc N., Lambert C., Volety A.K., Soudant P. (2012) Reactive oxygen species in unstimulated hemocytes of the Pacific oyster Crassostrea gigas: a mitochondrial involvement. PLoS One, 7(10): e46594

Gerdol M., Gomez-Chiarri M., Castillo M.G., Figueras A., Fiorito G., Moreira R., Novoa B., Pallavicini A., Ponte G., Roumbedakis K., Venier P., Vasta G. R. (2018) Immunity in molluscs: recognition and effector mechanisms, with a focus on bivalvia. Advances in comparative immunology. Springer, Cham, p. 225-341

Hernández-Méndez L.S., Castro-Longoria E., Araujo-Palomares C.L., García-Esquivel Z., Castellanos-Martínez S. (2020) Hemocyte cell types of the Cortes Geoduck, Panopea globosa (Dall 1898), from the Gulf of California, Mexico. Fish \& Shellfish Immunology, 100: 230-237

Hine P. M. (1999) The inter-relationships of bivalve haemocytes. Fish \& Shellfish Immunology, 9(5): $367-385$

Hinzmann M., Lopes-Lima M., Cerca F., Correia A., Machado J., Vilanova M. (2017) Identification of distinct haemocyte populations from the freshwater bivalves swan mussel (Anodonta cygnea) and duck mussel (Anodonta anatina) using wheat-germ agglutinin. Canadian Journal of Zoology, 95(12): 937-947

Karetin Y. A., Kalitnik A. A., Safonova A.E., Cicinskas E. (2019) Description and classification of bivalve mollusks hemocytes: a computational approach. PeerJ, 7: e7056

Lambert C., Soudant P., Choquet G., Paillard C. (2003) Measurement of Crassostrea gigas hemocyte oxidative metabolism by flow cytometry and the inhibiting capacity of pathogenic vibrios. Fish \& Shellfish Immunology, 15(3): 225-240

Le Guernic A., Geffard A., Le Foll F., Ladeiro M.P. (2020) Comparison of viability and phagocytic responses of hemocytes withdrawn from the bivalves Mytilus edulis and Dreissena polymorpha, and exposed to human parasitic protozoa. International Journal for Parasitology, 50(1): 75-83

Muttray A.F., Vassilenko K. (2018) Mollusca: disseminated neoplasia in bivalves and the p53 protein family. Advances in comparative immunology. Springer, Cham, p. 953-979

Nakahara Y., Shimura S., Ueno C., Kanamori Y., Mita K., Kiuchi M., Kamimura M. (2009) Purification and characterization of silkworm hemocytes by flow cytometry. Developmental \& Comparative Immunology, 33(4): 439-448

Ottaviani E., Franchini A., Barbieri D., Kletsas D. (1998) Comparative and morphofunctional studies on Mytilus galloprovincialis hemocytes: presence of two aging-related hemocyte stages. Italian Journal of Zoology, 65(4): 349-354

Parrino V., Costa G., Cannavà C., Fazio E., Bonsignore M., Concetta S., Piccione G., Fazio F. (2019) Flow cytometry and micro-Raman spectroscopy: Identification of hemocyte populations in the mussel Mytilus galloprovincialis (Bivalvia: Mytilidae) from Faro Lake and Tyrrhenian Sea (Sicily, Italy). Fish \& Shellfish Immunology, 87: 1-8

Pipe R.K. (1990) Hydrolytic enzymes associated with the granular haemocytes of the marine mussel Mytilus edulis. The Histochemical Journal, 22(11): 595-603

Pipe R.K. (1992) Generation of reactive oxygen metabolites by the hemocytes of the mussel Mytilus edulis. Developmental \& Comparative Immunology, 16(2-3): 111-122

Rigonato J., Mantovani M. S., Jordao B. Q. (2005) Comet assay comparison of different Corbicula fluminea (Mollusca) tissues for the detection of genotoxicity. Genetics and Molecular Biology, 28(3): $464-468$ 
Rolton A., Delisle L., Berry J., Venter L., Webb S. C., Adams S., Hilton Z. (2020) Flow cytometric characterization of hemocytes of the flat oyster, Ostrea chilensis. Fish \& Shellfish Immunology, 97: 411-420

Takahashi K. G., Izumi-Nakajima N., Mori K. (2017) Unique phagocytic properties of hemocytes of Pacific oyster Crassostrea gigas against yeast and yeast cell-wall derivatives. Fish \& Shellfish Immunology, 70: 575-582

Travers M. A., Da Silva P. M., Le Goïc N., Marie D., Donval A., Huchette S., Koken M., Paillard C. (2008) Morphologic, cytometric and functional characterisation of abalone (Haliotis tuberculata) haemocytes. Fish \& Shellfish Immunology, 24(4): 400-411

Van der Knaap W.P.W., Adema C. M., Sminia T. (1993) Invertebrate blood cells: morphological and functional aspects of the haemocytes in the pond snail Lymnaea stagnalis. Comparative Haematology International, 3(1): 20-26

Wang W., Li M., Wang L., Chen H., Liu Z., Jia Z., Qiu L., Song L. (2017) The granulocytes are the main immunocompetent hemocytes in Crassostrea gigas. Developmental \& Comparative Immunology, 67: 221-228 